With a project such as this that crosses various disciplinary boundaries, it was sometimes challenging to know where to turn for input and guidance along the way. But there were several people whose support and counsel were indispensable. On the home front, Anna Cameron provided a valuable sounding board for varied thoughts and ideas, as well as love and encouragement at each step along the winding path from the project's initial conception to final conclusion. James Côté of the Department of Sociology at Western University offered incisive comments on an early draft of the work and consistent encouragement through subsequent stages of revision and review. Anonymous readers for Cornell University Press offered constructive critiques from diverse disciplinary perspectives that helped in shoring up different dimensions of the work, while Emily Andrew, my editor at the press, provided sharp-eyed editing advice as the finishing touches were being applied, as well as guiding the review and publication process with characteristic dispatch and good cheer. Financial support toward publication was provided by a grant from the Harrison McCain Foundation at the University of New Brunswick.

My thanks to all for their warm encouragement and support. 



\section{TEEN SPIRIT}


